\title{
Restrictions of the Islamic Financial System and Counterpart Financial Support for Xinjiang
}

\author{
Helen Hui HUANG \\ Faculty of Business Administration, University of Regina, Regina, SK, S4S 0A2, Canada \\ E-mail: helen.huang@uregina.ca \\ Hui WANG \\ School of Economics and Management, Beijing Information Science and Technology University, \\ Beijing 100192, China \\ E-mail: susanwang@vip.sina.com \\ Zexin WEI \\ School of Economics and Management, Beijing Information Science and Technology University, \\ Beijing 100192, China \\ E-mail: 932980627@qq.com \\ Jiawei XIA \\ School of Finance, Renmin University of China, Beijing 100872, China \\ E-mail: a1994.35@qq.com

\section{Shunming ZHANG*} \\ School of Finance, Renmin University of China, Beijing 100872, China \\ E-mail: szhang@ruc.edu.cn
}

\begin{abstract}
This paper builds a theoretical framework of two-period general equilibrium model to explore whether 1) the restrictions of the Islamic financial system (RIFS) limit economic development in Xinjiang and 2) counterpart financial support for Xinjiang (CFSX) promotes economic development and social stability. First, we introduce above mentioned restrictions caused by Islamic beliefs into a general equilibrium model and modify Islamic agents' budget constraints to define the benchmark equilibrium. Comparing the benchmark equilibrium with the perfect equilibrium, in which these restrictions are removed, we discover the RIFS paradox that RIFS undermine the social welfare and income of Muslims. Second, the financial support is introduced into the pattern of benchmark equilibrium as an exogenous variable to model its impact and hence we define the CFSX equilibrium. A series of policy analyses implies that the CFSX strategy improves living standards and social welfare in Xinjiang.
\end{abstract}

Keywords islamic religious beliefs; general equilibrium; benchmark equilibrium; perfect equilibrium; economic development

Received October 22, 2020, accepted January 19, 2021

Supported by the National Natural Science Foundation of China $(71573220,71773123)$

* Corresponding author 


\section{Introduction}

Interest is the compensatory expenses paid by the debtor to the creditor. On the one hand, interest is the price of borrowing money for debtors; on the other hand, interest can partially decrease the credit risk and opportunity cost of debt investments for investors who provide loads or buy bonds. In modern society, paying interest for deposits and charging interest for loans are common practices for banks globally. However, three of the major religions in the world have different views on interest. In Buddhism, there is no discussion about interest. Christians believe that usury is evil and a "malignant tumor" contrary to the notion of charity in Christianity. Islam forbids the collection of interest with the Qur'an stating that "Allah permits trading and prohibits interest". In the Qur'an, the Scriptures prohibiting interest (e.g., 2:275-279, 3:130, 4:161, 30:39.) have deeply affected the Islamic world and led to a unique financial system. Islamic banks prohibit the collection and payment of interest, and thus they mainly develop their business through participation in the shareholding system and mark-up system. The prohibition of collecting and payment of interest by Islamic banks has had a substantial impact on the production and life of Islamic nations ${ }^{[1,2]}$. Indeed, a considerable number of Muslims have never or rarely been exposed to financial services (including financial transactions, banking and insurance). This kind of borrowing constraint reduces their income and social welfare, thus lowering their standard of living ${ }^{[3,4]}$. Therefore, external economic support is needed to weaken or even eliminate the negative effects of the borrowing constraints imposed by religious beliefs, so that Muslims can enjoy the same level of income and social welfare as non-Muslims without such constraints.

In the beginning of 2012, the global population of Muslims exceeded 1.6 billion, accounting for $23.19 \%$ of the world's population. Muslims are distributed across 204 countries and regions. In 28 countries, the majority of the population is Islamic, and Muslims account for more than $50 \%$ of their country's population in other 35 countries. China's Muslim population is 20.32 and 23.14 million in 2000 and 2010, accounting for just $1.64 \%$ and $1.73 \%$ of the country's population, respectively. Of the 10 ethnic groups in China who follow Islam ${ }^{1}$, the most populous are Hui and Uygur, the population of which accounts for nearly $90 \%$ of the Muslim population in China. The Xinjiang Uygur Autonomous Region (hereafter referred to as Xinjiang) is one of the five major ethnic autonomous regions in China ${ }^{2}$. Of the 21.813 million residents in Xinjiang in 2010, the Uygur population is the largest (10.528 million), more than the Han population (8.473 million). In 2016, the proportion of Muslims in Xinjiang has reached 59.77\%. This setting provides us with a unique window to study the constriant to Xinjiang's Islamic economic development from the perspective of the restrictions of the Islamic financial system (RIFS). Since the Muslim

\footnotetext{
${ }^{1}$ These 10 ethnic groups are Hui, Uygur, Kazak, Uzbek, Tajik, Tatar, Kirgiz, Salar, Dongxiang, and Baoan. In contrast to the widespread distribution of the Hui population, the other ethnic groups are mainly distributed in the northwest of China.

${ }^{2}$ The 12 provinces, autonomous regions and municipalities in which Muslims are most concentrated are (in descending order) Xinjiang Uygur Autonomous Region, Ningxia Hui Autonomous Region, Gansu Province, Henan Province, Qinghai Province, Yunnan Province, Hebei Province, Shandong Province, Anhui Province, Liaoning Province, Beijing Municipalities, and Inner Mongolia Autonomous Region. The number of Muslims in Xinjiang in 2000 is 10.70 million (accounting for $57.99 \%$ of the local population) compared with only 1.865 and 1.669 million in Ningxia Hui Autonomous Region and Gansu Province, respectively (accounting for $33.99 \%$ and $6.64 \%$ of the local population).
} 
population globally is sufficiently large, studying how religious beliefs affect interest reception and payment at a global scale is of great significance.

Since China's reform and opening up, GDP in Xinjiang has increased year on year. Per capita GDP fall from the 19th place in the pre-reform period to 25th in 2016. This indicates that Xinjiang's economic development lags behind that of other provinces, autonomous regions and municipalities in China. In 2012, Xinjiang's primary industry accounts for $17.69 \%$ of GDP (considerably higher than the national level of 5.59\%), whereas its tertiary industry is $34.62 \%$ (compared with the national level of $45.38 \%$ ). Hence, Xinjiang's industrial structure is backward, and the lagging development of the service industry has affected the upgrading of its industrial structure and economic development.

To analyze the reasons behind the lag in Xinjiang's economic development, geography is usually the first consideration. Xinjiang is located in the northwest of China and accounts for onesixth of China's total land area (1,631,585 square kilometers). It is bordered by eight countries including Russia and Kazakhstan, as well as Mongolia, Kyrgyzstan, Tajikistan, Afghanistan, Pakistan, and India. Xinjiang's land border is more than 5,600 kilometers, accounting for onequarter of the national land border. In summary, it is the largest province in China with the longest land border and the largest number of neighboring countries. Second, Xinjiang's coal and natural gas reserves are the highest in the country, while its oil reserves are second. In addition, solar energy and wind resources are abundant. Hence, Xinjiang has not only outstanding geographical advantages, but also obvious energy advantages. Therefore, Xinjiang's lack of economic development is not driven by a weak geographical location or a shortage of resources. Hence, to analyze economic development in Xinjiang, we must examine non-economic factors such as population and culture. We bridge the gap in the literature on this topic by studying the influence of the restrictions of the Islamic financial system on Xinjiang's economic development. Effective economic aid (including science and technology aid, education aid.) could comprehensively improve Xinjiang's economic status and raise its social stability.

To support the economic development of Xinjiang and solve basic livelihood issues such as employment, education, and housing, the state initiates its "counterpart financial support to Xinjiang" policy in March 30, 2010 (termed CFSX hereafter). The state has vigorously supported the CFSX to enable Xinjiang to achieve a leap forward and improve social prosperity. The CFSX is expected to help address the differences brought about by different cultures and religious beliefs in Xinjiang to achieve multiculturalism, a peaceful coexistence, and healthy development. At the same time, it aims to support the development of Xinjiang's characteristic and advantageous industries and help improve its "hematopoietic" function. The National Science and Technology Assistance Project in Xinjiang, an important part of CFSX, has also played a crucial role in supporting and leading the overall deployment of aid work in Xinjiang. At the same time, the Ministry of Education launched the "Assistance Construction Project for Xinjiang" to deepen the CFSX, optimize the structure of Xinjiang's universities, promote discipline construction, and accelerate the development and improve the quality of higher education.

Despite the widespread use of general equilibrium theory ${ }^{[5,6]}$ over the past half-century, no religious beliefs have been involved in its development. Religious beliefs not only change con- 
sumer preferences (as well as utility functions), but may also change budget constraints, which makes problems complex. In this paper, we use general economic equilibrium theory to study the RIFS that constrain Xinjiang's economic development and the CFSX that promotes stable development in Xinjiang - Using a two-period (the simplest dynamic) general equilibrium model $^{[7,8]}$ to simulate the prohibition of interest under Islam and impact of the CFSX on the life and welfare of Muslims in China.

This article first distinguishes Muslims from non-Muslims as two types of economic agents. As the distributions of their capital and labor factor endowment are different, we assume that every type of agents is homogeneous and that there is no financial market (i.e., no uncertainty) to simplify the model.

For each period, this paper selects the constant elasticity of substitution (CES) production function and obtains the production factors' (capital and labor factors) demand and price (i.e., return on capital and wage rate) by minimizing the production cost in the case of a given production function (or equivalently, maximizing the production function in a given production cost situation), which these should meet the zero profit condition ${ }^{[9,10]}$. The Qur'an allows capital elements to be profitable through production. We assume the prices of the three types of commodities (such as primary, secondary and tertiary industries) to be equal, otherwise the production factors will flow to the industry with the highest returns. We assume that the utility function of each type of agent is a nested function form. For two periods, the utility function is in the form of the CES function; it is also in the form of the CES function for each period. The budget constraints of each type of agent are represented in two periods. In the first period, income is obtained through initial endowments and used for consumption and borrowing; in the second period, income is obtained through initial endowments and borrowing in the first period, and used for consumption. Hence, the budget constraints of the two types of agents are different. Muslims only have private loans in the first period, and no interest in the second period, whereas non-Muslims can borrow money through financial intermediaries (such as banks) in the first period and gain strictly positive interest in the second period (we can even assume different lending rates). Then, we can solve the demand function of the two types of agents. In this way, we can define the general economic equilibrium through the clearing of the commodity and factor markets. We consider two cases. In the benchmark equilibrium case, the RIFS make Muslims use private lending by enforcing interest restrictions (i.e., the benchmark equilibrium defined above). In the second case, we assume that both Muslims and non-Muslims face the same interest rate and can borrow through financial intermediaries. The equilibrium of this situation is called perfect equilibrium. Comparing the equilibria of these two cases, we find that under the same parameters, the income and social welfare of Muslims in the benchmark equilibrium case are smaller than those in the perfect equilibrium case. This creates a paradox in that the RIFS harms the interests of Muslim agents.

Next, to account for the CFSX in the model, we add an exogenous variable into the benchmark equilibrium. Under the same conditions, each type of agents can obtain more income from the CFSX in two periods and new demand functions can be calculated, allowing us to obtain a third type of equilibrium, called the CFSX equilibrium, which changes with income under the CFSX. We analyze the threshold value of CFSX income at which the social welfare 
of Muslims in the CFSX equilibrium can reach the ideal equilibrium. Then, we conduct policy analyses and simulate the growth in the CFSX. In each of the 10 simulations, CFSX income is $100 \%$ more than that in previous simulation. The relationships between CFSX and Xinjiang's social stability and economic development are finally discussed ${ }^{[11-21]}$.

The remainder of the paper proceeds as follows. Section 2 builds the basic model. Section 3 shows actual data and calibrates the parameters. Section 4 compares the benchmark equilibrium with the perfect equilibrium and discusses the RIFS. Section 5 discusses the CFSX equilibrium. Section 6 presents a sensitivity analysis. Section 7 concludes.

\section{Basic General Equilibrium Model}

In this paper we consider the Muslim consumers in Xinjiang and non-Muslim individuals present in the general equilibrium framework, so there exist two classes of consumers. Note that Muslim must obey the teachings of the Qur'an and prohibit the acquisition of various forms of interest, then these two classes of consumers, the Muslim and non-Muslim consumers, have different economic behaviors because of religious beliefs. Muslims cannot receive any interest benefits, while non-Muslims, as economic agents, may obtain lawful interest incomes. The interest earning must exist in dynamic models, so the simplest dynamic models are described in two-period economic frameworks.

We establish a two-period general equilibrium model with three sectors of production (primary, secondary, and tertiary), two input factors of production (labor and capital), and two classes of consumers (Muslims and non-Muslims). The interest rate, a key variable in our research, is described in a dynamic framework; then, this paper simplifies the dynamic model using a two-period scenario.

At each period, the production of each sector takes place according to a constant-returnsto-scale, constant-elasticity-of-substitution (CES) production function. Specifically, at $t=0,1$, the production functions are given by the form of the CES function of the two input factors (labor and capital),

$$
\begin{aligned}
Y_{l}^{t}=Q_{l}^{t}\left(F_{l L}^{t}, F_{l K}^{t}\right) & =\phi_{l}^{t}\left\{\sum_{j=L, K} \delta_{l j}^{t}\left[F_{l j}^{t}\right]^{\xi_{l}^{t}}\right\}^{\frac{1}{\xi_{l}^{t}}} \\
& =\phi_{l}^{t}\left\{\delta_{l L}^{t}\left[F_{l L}^{t}\right]^{\xi_{l}^{t}}+\delta_{l K}^{t}\left[F_{l K}^{t}\right]^{\xi_{l}^{t}}\right\}^{\frac{1}{\xi_{l}^{t}}}, \quad l=1,2,3,
\end{aligned}
$$

where $Y_{l}^{t}$ denotes the production output of sector $l, F_{l j}^{t}$ represents the labor and capital factor inputs $(j=L, K), \phi_{l}^{t}$ is the scale or unit parameter, $\delta_{l j}^{t}$ is the distribution parameter with $\sum_{j=L, K} \delta_{l j}^{t}=1$, and $\sigma\left(\xi_{l}^{t}\right)=\frac{1}{1-\xi_{l}^{t}}$ is the elasticity of factor substitution ${ }^{3}$. The total cost of the labor and capital factor inputs is

$$
C_{l}^{t}\left(F_{l L}^{t}, F_{l K}^{t}\right)=\sum_{j=L, K} B_{j}^{t} F_{l j}^{t}=B_{L}^{t} F_{l L}^{t}+B_{K}^{t} F_{l K}^{t}, \quad l=1,2,3,
$$

where $B_{j}^{t}$ is the price of labor and capital $j=L, K$. The factor input cost minimization problem with the constraint of production function (or equivalently, its dual problem, the production

$$
{ }^{3} \text { Hence, } \xi_{l}^{t}=\frac{\sigma\left(\xi_{l}^{t}\right)-1}{\sigma\left(\xi_{l}^{t}\right)} .
$$


output maximization problem with the constraint of factor input cost function) implies the following labor and capital factor inputs:

$$
F_{l j}^{t}=\frac{Y_{l}^{t}}{\phi_{l}^{t}}\left(\frac{\delta_{l j}^{t}}{B_{j}^{t}}\right)^{\frac{1}{1-\xi_{l}^{t}}}\left[\sum_{j=L, K}\left(\frac{\delta_{l j}^{t}}{B_{j}^{t}}\right)^{\frac{1}{1-\xi_{l}^{t}}} B_{j}^{t}\right]^{-\frac{1}{\xi_{l}^{t}}}, \quad l=1,2,3, \quad j=L, K .
$$

For the two classes of consumers, we adopt nested constant-elasticity-of-substitution (CES) utility functions. Specifically, for $i=0,1$, the CES utility functions are given by

$$
U_{i}=\left\{\sum_{t=0}^{1} \alpha_{i}^{t}\left[U_{i}^{t}\right]^{\eta_{i}}\right\}^{\frac{1}{\eta_{i}}}
$$

where $U_{i}$ denotes total utility, $U_{i}^{t}$ represents utility at period $t, \alpha_{i}^{t}$ is the share parameter of time $t$ with $\sum_{t=0}^{1} \alpha_{i}^{t}=1$, and $\sigma\left(\eta_{i}\right)=\frac{1}{1-\eta_{i}}$ is the elasticity of utility substitution ${ }^{4}$; at $t=0,1$, the utility function is also set to the form of the CES functions

$$
U_{i}^{t}=\left\{\sum_{l=1}^{3} \beta_{i l}^{t}\left[X_{i l}^{t}\right]^{\zeta_{i}^{t}}\right\}^{\frac{1}{\zeta_{i}^{t}}},
$$

where $X_{i l}^{t}$ represents the consumption quantity of three commodities, $\beta_{i l}^{t}$ is the share parameter with $\sum_{l=1}^{3} \beta_{i l}^{t}=1$, and $\sigma\left(\zeta_{i}^{t}\right)=\frac{1}{1-\zeta_{i}^{t}}$ is the elasticity of utility substitution ${ }^{5}$.

Non-Muslim consumers, as economic agents, may obtain lawful interest incomes, then their budget constraints, for $i=0$, are given by

$$
\left\{\begin{array}{l}
\sum_{l=1}^{3} P_{l}^{0} X_{0 l}^{0}+M_{0}=\sum_{j=L, K} B_{j}^{0} E_{0 j}^{0}, \\
\sum_{l=1}^{3} P_{l}^{1} X_{0 l}^{1}=\sum_{j=L, K} B_{j}^{1} E_{0 j}^{1}+(1+R) M_{0},
\end{array}\right.
$$

where $P_{l}^{t}$ is the price of the commodities $(t=0,1$ and $l=1,2,3), E_{0 j}^{t}$ is the endowment of labor and capital $(t=0,1$ and $j=L, K), M_{0}$ is the wealth transfer from period 0 to period 1 , and $R$ is the interest rate from period 0 to period 1. In budget constraints Equation (2.6), $\sum_{l=1}^{3} P_{l}^{t} X_{0 l}^{t}$ is the consumption value of non-Muslim consumer $i=0$ at period $t=0,1$, whereas $\sum_{j=L, K} B_{j}^{t} E_{0 j}^{t}$ is the endowment value (initial wealth) of non-Muslim consumer $i=0$ at period $t=0,1$. However, as Muslim consumers cannot receive any interest benefits, their budget constraints, for $i=1$, are given by

$$
\left\{\begin{array}{l}
\sum_{l=1}^{3} P_{l}^{0} X_{1 l}^{0}+M_{1}=\sum_{j=L, K} B_{j}^{0} E_{1 j}^{0}, \\
\sum_{l=1}^{3} P_{l}^{1} X_{1 l}^{1}=\sum_{j=L, K} B_{j}^{1} E_{1 j}^{1}+M_{1},
\end{array}\right.
$$

\footnotetext{
${ }^{4}$ Hence, $\eta_{i}=\frac{\sigma\left(\eta_{i}\right)-1}{\sigma\left(\eta_{i}\right)}$.

${ }^{5}$ Hence, $\zeta_{i}^{t}=\frac{\sigma\left(\zeta_{i}^{t}\right)-1}{\sigma\left(\zeta_{i}^{t}\right)}$.
} 
where $E_{1 j}^{t}$ is the endowment of labor and capital $(t=0,1$ and $j=L, K)$, and $M_{1}$ is the wealth transfer from period 0 to period 1. In budget constraints Equation (2.7), $\sum_{l=1}^{3} P_{l}^{t} X_{1 l}^{t}$ is the consumption value of Muslim consumer $i=1$ at period $t=0,1$, whereas $\sum_{j=L, K} B_{j}^{t} E_{1 j}^{t}$ is the endowment value (initial wealth) of Muslim consumer $i=1$ at period $t=0,1$. We merger budget constraints Equations (2.6) and (2.7) into one general form for the two classes of consumers,

$$
\left\{\begin{array}{l}
\sum_{l=1}^{3} P_{l}^{0} X_{i l}^{0}+M_{i}=\sum_{j=L, K} B_{j}^{0} E_{i j}^{0}, \\
\sum_{l=1}^{3} P_{l}^{1} X_{i l}^{1}=\sum_{j=L, K} B_{j}^{1} E_{i j}^{1}+\left(1+\theta_{i} R\right) M_{i},
\end{array} \quad i=0,1 .\right.
$$

In particular, $\theta_{i}$ is an indicator function for non-Muslim consumers, $\theta_{0}=1$ and $\theta_{1}=0$.

$$
\theta_{i}= \begin{cases}1, & \text { for } \quad i=0 \\ 0, & \text { for } \quad i=1\end{cases}
$$

We assume that

$$
\theta_{i}^{t}= \begin{cases}0, & \text { for } t=0 \\ \theta_{i}, & \text { for } t=1\end{cases}
$$

The budget constraint can be rewritten as

$$
\sum_{t=0}^{1} \sum_{l=1}^{3}\left(1+\theta_{i}^{t} R\right) P_{l}^{t} X_{i l}^{t}=\sum_{t=0}^{1} \sum_{j=L, K}\left(1+\theta_{i}^{t} R\right) B_{j}^{t} E_{i j}^{t} .
$$

Then the solution to the maximization problem of utility function is

$$
\begin{aligned}
& X_{i l}^{t} \\
&=\frac{\left[\sum_{t=0}^{1} \sum_{j=L, K}\left(1+\theta_{i}^{t} R\right) B_{j}^{t} E_{i j}^{t}\right]\left(\frac{P_{l}^{t} \beta_{i 1}^{t}}{P_{1}^{t} \beta_{i l}^{t}}\right)^{\frac{1}{\epsilon_{i}^{t}-1}}\left\{\frac{\left(1+\theta_{i}^{t} R\right) P_{1}^{t}}{\alpha_{i}^{t} \beta_{i 1}^{t}}\left[\sum_{l=1}^{3} \beta_{i l}^{t}\left(\frac{P_{l}^{t} \beta_{\beta_{1}}^{t}}{P_{1}^{t} \beta_{i l}^{t}}\right)^{\frac{\zeta_{i}^{t}}{\zeta_{i}^{t}-1}}\right]^{1-\frac{\eta_{i}}{\zeta_{i}^{t}}}\right\}^{\frac{1}{\eta_{i}-1}}}{\sum_{t=0}^{1} \sum_{l=1}^{3}\left(1+\theta_{i}^{t} R\right) P_{l}^{t}\left(\frac{P_{l}^{t} \beta_{i 1}^{t}}{P_{1}^{t} \beta_{i l}^{t}}\right)^{\frac{1}{\zeta_{i}^{t}-1}}\left\{\frac{\left(1+\theta_{i}^{t} R\right) P_{1}^{t}}{\alpha_{i}^{t} \beta_{i 1}^{t}}\left[\sum_{l=1}^{3} \beta_{i l}^{t}\left(\frac{P_{l}^{t} \beta_{i 1}^{t}}{P_{1}^{t} \beta_{i l}^{t}}\right)^{\frac{\zeta_{i}^{t}}{\epsilon_{i}^{t}-1}}\right]^{1-\frac{\eta_{i}}{\zeta_{i}^{t}}}\right\}^{\frac{1}{\eta_{i}-1}}} .
\end{aligned}
$$

The general economic equilibrium is defined as the full utilization of the stock of each element (i.e., there is no redundant element). The general economic equilibrium conditions are: 1) Zero profit conditions; 2) Commodity market clearing; and 3) factor market clearing.

1) Zero Profit Conditions

$$
P_{l}^{t} Y_{l}^{t}=\sum_{j=L, K} B_{j}^{t} F_{l j}^{t}, \quad t=0,1, \quad l=1,2,3
$$

2) Markets Clearing for Goods

$$
Y_{l}^{t}=\sum_{i=0}^{1} X_{i l}^{t}, \quad t=0,1, \quad l=1,2,3
$$


3) Markets Clearing for Factors

$$
\sum_{l=1}^{2} F_{l j}^{t}=\sum_{i=0}^{1} E_{i j}^{t}, \quad t=0,1, \quad j=L, K
$$

And

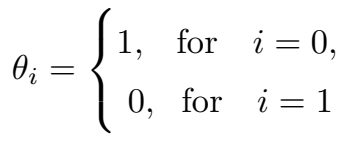

is the actual situation in Xinjiang and this equilibrium is called the benchmark equilibrium.

\section{Actual Data and Benchmark Parameter Calibration}

\subsection{Data}

The data used in this paper come from the Xinjiang Statistical Yearbook and the China Statistical Yearbook. Some data are calculated by the authors. Table 1 shows the macroeconomic data in 2009 and 2010.

\begin{tabular}{|c|c|c|c|c|c|c|}
\hline & \multicolumn{2}{|c|}{ The primary industry } & \multicolumn{2}{|c|}{ The secondary industry } & \multicolumn{2}{|c|}{ The tertiary industry } \\
\hline & 2009 & 2010 & 2009 & 2010 & 2009 & 2010 \\
\hline GDP (billion) & 75.974 & 107.863 & 192.959 & 259.215 & 158.772 & 176.669 \\
\hline Labor income (billion) & 73.870314 & 105.041987 & 38.907528 & 54.826161 & 94.469305 & 104.853529 \\
\hline Wage rate & 1.000000 & 1.170026 & 1.000000 & 1.170026 & 1.000000 & 1.170026 \\
\hline Return of investment & 1.000000 & 1.000000 & 1.000000 & 1.000000 & 1.000000 & 1.000000 \\
\hline Return on savings & \multicolumn{6}{|c|}{0.023041} \\
\hline \multicolumn{7}{|c|}{ Individual consumption proportion } \\
\hline Non-Muslims & 0.408277 & 0.407535 & 0.508593 & 0.507824 & 0.500000 & 0.500000 \\
\hline Muslims & 0.591723 & 0.592465 & 0.491407 & 0.492176 & 0.500000 & 0.500000 \\
\hline
\end{tabular}

Table 1 Macroeconomic data

The process of data acquisition and calculation is as follows:

1) GDP is taken from the Xinjiang Statistical Yearbook 2017.

2) Labor income is the product of wage rate and labor inputs.

3) Salary level is calculated from the Xinjiang Statistical Yearbook 2017. The salary level in 2009 is set to 1 . Then the salary level in 2010 is equal to the ratio of the average labor compensation of the employed in Xinjiang in 2010 to that in 2009.

4) Return on investment is set to 1 .

5) Return on savings is the weighted average of the benchmark interest rate of RMB deposits and one-year fixed deposit interest rate from the People's Bank of China over the sample period (weighted by the number of days). 
6) The proportion of household consumption expenditure is calculated from the Xinjiang Statistical Yearbook 2017.

As shown in Table 1, the GDP of Xinjiang in 2010 is significantly higher than that in 2009, especially in the secondary industry (increasing from 192.959 billion yuan in 2009 to 259.215 billion yuan in 2010). The GDP of the primary industry rises from 75.974 billion yuan to 107.863 billion yuan, and it rises from 158.772 billion yuan to 176.66 billion yuan in the tertiary industry. From 2009 to 2010, the GDP of Xinjiang increases by $27.13 \%$ overall. The labor income in the three industries in Xinjiang also increases. Among them, the primary industry grows the fastest, and followed by the secondary industry.

Indeed, the industrial structure of Xinjiang is different from that across China because of the lack of economic development in the region. Since the reform and opening up, the proportion of GDP in Xinjiang's primary industry has been declining from $21.13 \%$ in 2000 to $19.84 \%$ in 2010 , and to $17.09 \%$ in 2016. However, the proportion of the primary industry in Xinjiang is still much larger than the country (9.5\%) in 2016. Since 2000, the GDP ratio of Xinjiang's secondary industry has experienced a trend of rising first (from $39.42 \%$ in 2000 to $49.50 \%$ in 2008 ) and then slowly declines to $37.79 \%$ in 2016 . Finally, the tertiary industry in Xinjiang has made remarkable progress. The proportion is increasing from $34.75 \%$ in 2006 to $45.12 \%$ in 2016.

\subsection{Parameter Calibration}

As shown in Table 2, the parameters to be calibrated in this paper are those of the production function $\phi_{l}^{t}, \delta_{l j}^{t}$, and $\xi_{l}^{t}$ and those of the utility function $\alpha_{i}^{t}, \beta_{i l}^{t}, \eta_{i}$, and $\zeta_{i}^{t}(t=0,1 ; l=1,2,3$; $j=L, K)$.

The labor quota of the primary industry is 0.855612 in 2009 and 0.868430 in 2010 . The distributions of the labor share of the secondary and tertiary industries are 0.334467 and 0.537936 in 2009 compared with 0.359067 and 0.566539 in 2010 . The distributions of the capital share are $0.144388,0.665533$, and 0.452046 in 2009 and $0.131570,0.640933$, and 0.433461 in 2010 for the primary, secondary, and tertiary industries, respectively. In 2009, the capital endowment of Muslims is set to 100 and the rate of increase is the same as the GDP growth rate for Xinjiang in the same period. Thus, the capital endowment of Muslims in 2010 is 127.131.

\section{Benchmark Equilibrium, Perfect Equilibrium and Restrictions of the Islamic Financial System (RIFS)}

We define the general economic equilibrium by clearing the commodity and factor markets. Then, we consider two cases. In the benchmark equilibrium case, RIFS means that Muslims use private lending owing to the interest use constraints. In the perfect equilibrium case, Muslims do not have to abide by these restrictions (i.e., Muslims and non-Muslims face the same interest and can both borrow from financial intermediaries).

In the benchmark equilibrium, the budget constraints of Muslims and non-Muslims are different. Using this budget constraint and utility maximization, the consumption demand of each type of goods is determined. Then, the zero profit conditions, commodity and factor markets clearing conditions are also determined. In this equilibrium, Muslims are restricted 
by their religious beliefs, and thus obtain lower income and welfare levels. If this restriction is removed, however, the economic indicators of Muslims (even non-Muslims) will improve. This equilibrium is defined as the perfect equilibrium: $\theta_{i}=1$ for $i=0,1$. Under these circumstances, two types of consumption demand for each commodity are obtained, leading to equilibrium - Zero profit conditions, commodity and factor markets clearing conditions. As shown in Table 3, the results of the "benchmark equilibrium" and "perfect equilibrium" can be found by substituting the previous data and calibration parameters into the model.

Table 2 Calibration

\begin{tabular}{|c|c|c|c|c|c|c|}
\hline & \multicolumn{2}{|c|}{ The primary industry } & \multicolumn{2}{|c|}{ The secondary industry } & \multicolumn{2}{|c|}{ The tertiary industry } \\
\hline & 2009 & 2010 & 2009 & 2010 & 2009 & 2010 \\
\hline \multicolumn{7}{|c|}{ 1) Production Function } \\
\hline$\phi_{l}^{t}$ & 1.328164 & 1.510833 & 1.802444 & 1.919428 & 1.981784 & 2.163506 \\
\hline$\delta_{l L}^{t}$ & 0.855612 & 0.868430 & 0.334467 & 0.359067 & 0.547936 & 0.566539 \\
\hline$\delta_{l K}^{t}$ & 0.144388 & 0.131570 & 0.665533 & 0.640933 & 0.452064 & 0.433461 \\
\hline$\xi_{l}^{t}$ & 0.500000 & 0.500000 & 0.500000 & 0.500000 & 0.500000 & 0.500000 \\
\hline \multicolumn{7}{|c|}{ 2) Utility Function } \\
\hline$\beta_{0 l}^{t}$ & 0.177504 & 0.194081 & 0.446046 & 0.466716 & 0.376450 & 0.339202 \\
\hline \multirow[t]{2}{*}{$\beta_{1 l}^{t}$} & 0.227645 & 0.247881 & 0.413577 & 0.430962 & 0.358778 & 0.321158 \\
\hline & & 2009 & & & 2010 & \\
\hline$\alpha_{0}^{t}$ & & 0.475519 & & & 0.524481 & \\
\hline$\alpha_{1}^{t}$ & & 0.469026 & & & 0.530974 & \\
\hline$\zeta_{i}^{t}$ & & 0.200000 & & & 0.200000 & \\
\hline$\eta_{i}$ & & 0.500000 & & & 0.500000 & \\
\hline \multirow[t]{2}{*}{ Endowment } & \multicolumn{4}{|c|}{ Non-Muslims } & \multicolumn{2}{|c|}{ Muslims } \\
\hline & & 2009 & 2010 & & 2009 & 2010 \\
\hline Labor & & 88.084 & 95.754 & & 119.163 & 130.499 \\
\hline Capital & & 120.458 & 151.894 & & 100.000 & 127.131 \\
\hline
\end{tabular}

\subsection{Benchmark Equilibrium}

The benchmark equilibrium is based on real data on economic development in Xinjiang and the fact that Muslims cannot obtain interest.

1) Income and Welfare

Taking 2009 as the reference year, total discounted income is 466.526 billion yuan for nonMuslims and 492.680 billion yuan for Muslims, whereas social welfare is 84.962 and 86.302 billion for non-Muslims and Muslims respectively. In 2010, the total population of Xinjiang is 21.8158 million: 12.9251 million and 8.8907 million for Muslims and non-Muslims, accounting for $59.25 \%$ and $40.75 \%$, respectively. However, there is no significant difference between the income and welfare levels of Muslims and non-Muslims. Under the benchmark equilibrium, per 
capita annual income is 5247.3 yuan for non-Muslims and 3811.8 yuan for Muslims. The per capita income of non-Muslims is thus higher than that for Muslims by $37.6594 \%$. Compared with non-Muslims, there is still room to improve Muslims' living standards.

2) Production

The output of the three industries in Xinjiang increases significantly in 2010. The primary industry increases from 75.974 to 107.863 billion yuan, an increase of $41.97 \%$; the secondary industry increases from 192.959 to 259.215 billion yuan, an increase of $34.37 \%$; and the tertiary industry increases from 158.772 to 176.669 billion yuan, an increase of $11.27 \%$. Under the benchmark equilibrium, the wage rate increases from 1.000000 to 1.170026 .

The labor input in the three industries is $73.870,38.908$ and 94.469 billion yuan respectively in 2009 and 89.777, 46.859, and 89.616 billion yuan in 2010. The growth rate of labor input is the fastest in the primary industry followed by the secondary industry; the growth rate is negative in the tertiary industry. This shows that the labor force moves from the tertiary industry to the primary and secondary industries. The high output of the primary industry in Xinjiang's GDP means that its primary industry still maintains high demand for labor. The capital inputs in the three industries are $2.104,154.510$, and 64.303 billion yuan respectively in 2009 and 2.821, 204.389, and 71.815 billion yuan respectively in 2010. In 2010, 85.95\% of the newly added capital input is invested in the secondary industry. Hence, in the industrial structure of Xinjiang, the primary industry has the largest demand for labor input, whereas the secondary industry has the largest demand for capital input.

3) Consumption

Non-Muslims' consumer demand in the three industries is $31.018,98.138$ and 79.386 billion yuan respectively in 2009, and 43.958, 131.636 and 88.335 billion yuan respectively in 2010 . Muslims' consumer demand is 44.956, 94.821 and 79.386 billion yuan respectively in 2009, which increases in 2010 (63.905, 127.579 and 88.335 billion yuan). From 2009 to 2010, the increase in Muslims' consumer demand is significantly higher than that of non-Muslims, suggesting that the living standards of both Muslims and non-Muslims, especially Muslims, improve rapidly. However, there remains a large gap between the consumer demand of Muslims and non-Muslims.

\subsection{Comparison of Perfect Equilibrium and Benchmark Equilibrium - RIFS}

The benchmark equilibrium case is unfavorable to Muslims because they cannot obtain interest. However, in the perfect equilibrium case, the budget constraints of Muslims and non-Muslims are the same and given by

$$
\left\{\begin{array}{l}
\sum_{l=1}^{3} P_{l}^{0} X_{i l}^{0}+M_{i}=\sum_{j=L, K} B_{j}^{0} E_{i j}^{0}, \\
\sum_{l=1}^{3} P_{l}^{1} X_{i l}^{1}=\sum_{j=L, K} B_{j}^{1} E_{i j}^{1}+\left(1+\theta_{i} R\right) M_{i} .
\end{array}\right.
$$

Here, $\theta_{0}=\theta_{1}=1$. Compared with the benchmark equilibrium, only the budget constraints have changed. The equilibrium in this case is the perfect equilibrium.

To compare the utility function and social welfare level in these different cases, we adopt the change in Hicksian equivalent income (termed the Hicksian equivalent variation, or HEV). 
Shoven and Whalley (1992) show that when the utility function is a linear homogeneous function, the HEV can be simplified to $\mathrm{EV}=\frac{U^{1}-U^{0}}{U^{0}} I^{0}$, where $I^{0}$ represents consumers' income before the policy change. Thus, the percentage of HEV relative to the base revenue is

$$
\mathrm{HEV}=\frac{\mathrm{EV}}{I^{0}} \times 100 \%=\frac{U^{1}-U^{0}}{U^{0}} \times 100 \% .
$$

1) Income and Welfare

In the perfect equilibrium, the social welfare and income levels of both Muslims and nonMuslims increase in 2010. The social welfare of non-Muslims and Muslims under perfect equilibrium is 84.965 and 86.304 billion, which is higher than that under the benchmark equilibrium (84.962 and 86.302 billion). Taking 2009 as the reference year, the total discounted income of non-Muslims and Muslims under perfect equilibrium is 469.683 and 496.028 billion yuan, respectively, which is significantly higher than that under the benchmark equilibrium (466.526 and 492.680 billion yuan). Under the perfect equilibrium, the per capita annual income of non-Muslims and Muslims is 5282.9 yuan and 3837.7 yuan respectively, slightly higher than that under that benchmark equilibrium (5247.3 yuan and 3811.8 yuan). Under the perfect equilibrium, the income of non-Muslims is higher than the income of Muslims by $37.6580 \%$. The gap between the per capita income and welfare of non-Muslims and Muslims is narrowing. Under the perfect equilibrium, savings reach 2.703 million yuan.

In conclusion, when the restriction of capital under the perfect equilibrium is lifted, savings rise, and the social welfare and income of non-Muslims and Muslims improve significantly. Hence, the existence of religious beliefs restricts the living standards of Xinjiang residents, especially Muslims.

2) Production

The outputs of the primary, secondary, and tertiary industries under the perfect equilibrium are 108.002, 259.139, and 176.606 billion yuan respectively in 2010. Compared with those under the benchmark equilibrium (107.863, 259.215, and 176.669 billion yuan), the output of the primary industry increases, whereas those of the secondary and tertiary industries decline slightly. Total output under the perfect equilibrium ( 543.747 billion yuan) is consistent with that under the benchmark equilibrium (543.747 billion yuan). Under the perfect equilibrium, the salary level is 1.184373 in 2010, greater than that under the benchmark equilibrium (1.170026).

The removal of interest restrictions transfers the labor and capital inputs further. Under the perfect equilibrium, the labor inputs in the three industries are 89.891, 46.811 and 89.551 billion yuan, respectively. Compared with those under the benchmark equilibrium (89.777, 46.859, and 89.616 billion yuan), the labor force flows from the secondary and tertiary industries to the primary industry. In terms of return on capital, the 1.011794 under the perfect equilibrium in 2010 is significantly larger than the 1.000000 under the benchmark equilibrium. Under the perfect equilibrium, the capital inputs in the three industries are 2.827, 204.369, and 71.829 billion yuan respectively in 2010. There is a certain difference from the capital input under the benchmark equilibrium $(2.821,204.389$, and 71.815 billion yuan) in 2010, and capital flows from the secondary industry to the primary and tertiary industries. Overall, the perfect equilibrium case is thus better than the benchmark equilibrium case. 
3) Consumption

In 2010, under the perfect equilibrium, non-Muslims' consumption demand in the three industries $(43.489,130.290$, and 87.412 billion yuan) is lower than that under the benchmark equilibrium (43.958, 131.636, and 88.335 billion yuan); for Muslims, consumption demand under the perfect equilibrium $(64.513,128.849$, and 89.194 billion yuan) is greater than that under the benchmark equilibrium $(63.905,127.579$, and 88.335 billion yuan), rising by $1.426,1.270$ and 0.859. Under the perfect equilibrium, Muslims' demand has increased significantly, which means that their living standards can be further improved in the perfect equilibrium case.

In summary, social welfare, total income, production outputs, factor inputs, and consumer demand are all different between the benchmark and perfect equilibria. There is also a huge difference in per capita income between non-Muslims and Muslims, while the social welfare of Muslims and non-Muslims under the perfect equilibrium is higher than that under the benchmark equilibrium, as shown as follows:

$$
\left.U_{1}\right|_{\theta_{0}=1, \theta_{1}=0} ^{\text {Benchmark Equilibrium }} \leqslant\left. U_{1}\right|_{\theta_{0}=1, \theta_{1}=1} ^{\text {Perfect Equilibrium }}
$$

Under the perfect equilibrium, the income and social welfare of Muslims and non-Muslims both improve, and the per capita income gap narrows. The labor factor is more invested in the primary industry, and the capital factor is more invested in the secondary industry. If the interest limit is removed, demand for all three industries will increase, especially the tertiary industry. Hence, the comparison between the perfect and benchmark equilibria shows that social development and economic operations in Xinjiang are restricted by the population's religious beliefs. Indeed, there are huge differences in production and living standard between Muslims and non-Muslims under these two types of equilibria.

We find that Muslims and non-Muslims lag behind in income and welfare because of religious doctrine as RIFS. Under the same parameters, the income and social welfare of Muslims in the

benchmark equilibrium case are lower than those in the perfect equilibrium case. This creates the paradox that these RIFS reduces the benefits of the Muslim population. In the next section, we use the real-world data on Xinjiang to carry out an example calculation using the general economic equilibrium model.

\section{Counterpart Support Policy and CFSX Equilibrium}

This paper has thus far shown that under the same parameter conditions, the income and social welfare levels of Muslims and non-Muslims are better than those under the benchmark equilibrium mainly because of religious beliefs rather than human factors. Muslims in Xinjiang have thus been unable to fully enjoy the fruits of social and economic development. If the government supports Xinjiang to eliminate the adverse effects of Islamic teachings, this will have a profound impact on the region's long-term stability and prosperity. This has inspired the central government to improve the living standards of Xinjiang residents, especially Muslims.

Through a certain amount of assistance, Xinjiang's residents, especially Muslims, can enjoy social welfare and income under the perfect equilibrium. Since the founding of the People's Republic of China, the central government and other provinces have continued to support Xinjiang. The CFSX launched in 1997 is the most typical case. However, support-related 
data are fully disclosed for the first time in 2010. In addition, in March 2010, the National Counterpart Support Xinjiang Work Conference is held in Beijing. Hence, this paper examines the two years of 2009 and 2010.

As noted already, the benchmark equilibrium case is unfavorable to Muslims. Given that they cannot receive interest, social welfare under the perfect equilibrium can be achieved only by giving Muslims and non-Muslims a certain endowment value and changing their budget constraints, under the premise of inconsistent budget constraints. Concerning the counterpart support, we can add an exogenous variable into the above benchmark equilibrium to obtain the CFSX equilibrium. Under the same conditions, the budget constraint of each type of agents increases her/his income because of the CFSX. The budget constraints on the equilibrium of support to Xinjiang are as follows:

$$
\left\{\begin{array}{l}
\sum_{l=1}^{3} P_{l}^{0} X_{0 l}^{0}+M_{0}=\sum_{j=L, K} B_{j}^{0} E_{0 j}^{0}+B_{K}^{0} H_{0}^{0}, \\
\sum_{l=1}^{3} P_{l}^{1} X_{0 l}^{1}=\sum_{j=L, K} B_{j}^{1} E_{0 j}^{1}+(1+R) M_{0}+B_{K}^{1} H_{0}^{1},
\end{array}\right.
$$

and

$$
\left\{\begin{array}{l}
\sum_{l=1}^{3} P_{l}^{0} X_{1 l}^{0}+M_{1}=\sum_{j=L, K} B_{j}^{0} E_{1 j}^{0}+B_{K}^{0} H_{1}^{0} \\
\sum_{l=1}^{3} P_{l}^{1} X_{1 l}^{1}=\sum_{j=L, K} B_{j}^{1} E_{1 j}^{1}+M_{1}+B_{K}^{1} H_{1}^{1}
\end{array}\right.
$$

where $H_{i}^{t}$ is counterpart assistance in period $t$.

Defining $\bar{E}_{i 1}^{t}=E_{i 1}^{t}$ and $\bar{E}_{i 2}^{t}=E_{i 2}^{t}+H_{i}^{t}, \bar{E}_{i t}^{t}$ is the factor endowment under the counterpart support. At this time $\theta_{0}=1, \theta_{1}=0$, and the consumer budget constraint can be rewritten as:

$$
\left\{\begin{array}{l}
\sum_{l=1}^{3} P_{l}^{0} X_{i l}^{0}+M_{i}=\sum_{j=L, K} B_{j}^{0} \bar{E}_{i j}^{0}, \\
\sum_{l=1}^{3} P_{l}^{1} X_{i l}^{1}=\sum_{j=L, K} B_{j}^{1} \bar{E}_{i j}^{1}+\left(1+\theta_{i} R\right) M_{i} .
\end{array}\right.
$$

Based on the reality of the existence of Muslims and non-Muslims in Xinjiang, we define the CFSX equilibrium as two types termed CFSX equilibrium 1 and CFSX equilibrium 2.

CFSX equilibrium 1: Ensure that the social welfare of Muslims is consistent with that under the perfect equilibrium.

CFSX equilibrium 2: Ensure that the social welfare of Muslims and non-Muslims is consistent with that under the perfect equilibrium.

Hence, the goals of the two types of CFSX equilibria and the calculated economic indicators are different. Table 3 shows the results. 


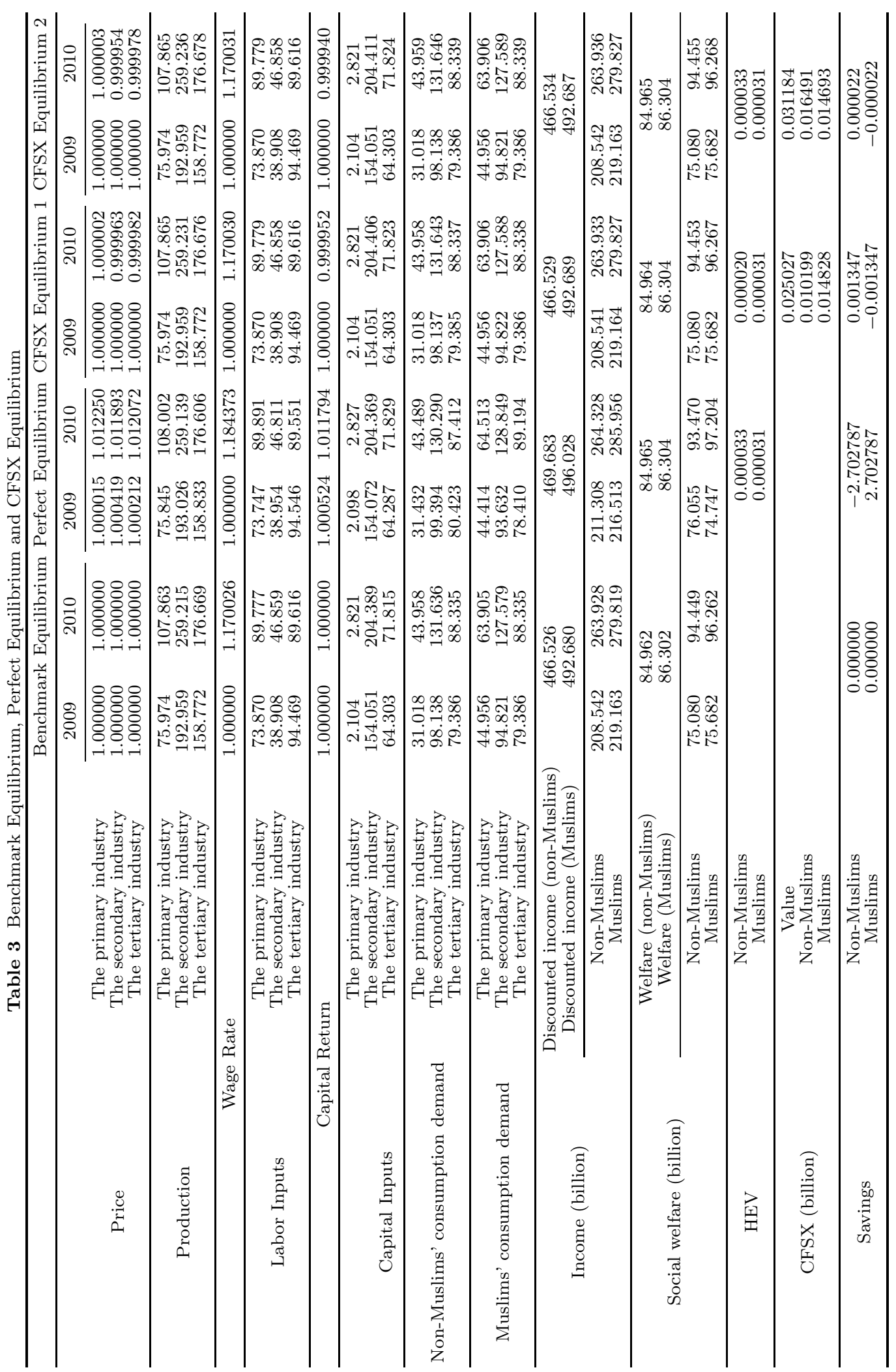




\subsection{Comparison of CFSX Equilibrium 1 and Perfect Equilibrium}

Under CFSX equilibrium 1, counterpart support is 25.027 million yuan (non-Muslims 10.199 million yuan and Muslims 14.828 million yuan).

$$
\left.U_{1}\right|_{\theta_{0}=1, \theta_{1}=0} ^{\text {CFSX Equilibrium } 1} \geqslant\left. U_{1}\right|_{\theta_{0}=1, \theta_{1}=1} ^{\text {Perfect Equilibrium }} .
$$

1) Income and Welfare

To ensure that total welfare of Muslims in CFSX equilibrium 1 is 86.304367 billion, which is consistent with that under the perfect equilibrium, non-Muslims in 2010 have slightly lower social welfare ( 84.963981 billion) than that under the perfect equilibrium ( 84.965077 billion). The HEV coefficients of Muslims and non-Muslims under CFSX equilibrium 1 and the benchmark equilibrium are $0.002016 \%$ and $0.003087 \%$. The coefficients under CFSX equilibrium 1 and the perfect equilibrium are $-0.001290 \%$ and $0.000000 \%$. Under CFSX equilibrium 1 , the welfare of Muslims and non-Muslims is both greater than that under the benchmark equilibrium. The welfare of the non-Muslims is less than that under the perfect equilibrium. The welfare of Muslims is equal to that under the perfect equilibrium.

Considering income, the income of the non-Muslims under CFSX equilibrium 1 in 2010 is 466.529 billion yuan, less than that under the perfect equilibrium (469.683 billion yuan) and nearly equal to that under the benchmark equilibrium (466.526 billion yuan); the income of Muslims under CFSX equilibrium 1 (492.689 billion yuan) is less than that under the perfect equilibrium (496.028 billion yuan), but significantly larger than the value under the benchmark equilibrium (492.680 billion yuan). In terms of per capita annual income, the value of nonMuslims under CFSX equilibrium 1 is 5247.4 yuan and the value of Muslims is 3811.9 yuan, both less than those under the perfect equilibrium (5282.9 yuan and 3837.7 yuan). The per capita income of non-Muslims is higher than that of religious residents by $37.6584 \%$. Under CFSX equilibrium 1, savings reach 1.347 million yuan.

2) Production

The implementation of the CFSX has promoted the production output of all three industries. Output under CFSX equilibrium 1 in 2010 (107.865, 259.231, and 176.676 billion yuan for the primary, secondary, and tertiary industries, respectively) differs from that under the perfect equilibrium (108.002, 259.139, and 176.606 billion yuan). The output of the primary industry is lower than that under the perfect equilibrium, whereas it is higher in the secondary and tertiary industries. Total output under CFSX equilibrium 1 (543.772 billion yuan) is higher than that under the perfect equilibrium ( 543.747 billion yuan). In 2010 , the wage rate under CFSX equilibrium 1 (1.170030) is lower than that under the perfect equilibrium (1.184373). The labor inputs of the three industries under CFSX equilibrium 1 are 89.779, 46.858 and 89.616 billion yuan respectively. Compared with the labor input under the perfect equilibrium (89.891, 46.811, and 89.551 billion yuan), the labor force flows from the primary industry to the secondary and tertiary industries. Total capital investment under CFSX equilibrium 1 in three industries is $2.821,204.406$, and 71.823 billion yuan. Compared with the values under the perfect equilibrium $(2.827,204.369$, and 71.829 billion yuan), capital flows from the primary and tertiary industries to the secondary industry. Under the perfect equilibrium, return on capital increases from 1.000524 in 2009 to 1.011794 in 2010, whereas return on capital under 
CFSX equilibrium 1 reduces from 1.000000 in 2009 to 0.999952 in 2010.

3) Consumption

The consumption levels of Muslims and non-Muslims have generally changed and the demand of Muslims has increased to a greater extent. The demand of non-Muslims under CFSX equilibrium 1 in 2010 (43.958, 131.643, and 88.337 billion yuan) is higher than that of the three industries under the perfect equilibrium $(43.489,130.290$, and 87.412 billion yuan). The demand of Muslims under CFSX equilibrium 1 in 2010 (63.906, 127.588, and 88.338 billion yuan) is lower than that under the perfect equilibrium (64.513, 128.849, and 89.194 billion yuan).

\subsection{Comparison of CFSX Equilibrium 2 and Perfect Equilibrium}

Under CFSX equilibrium 2, total counterpart support is 31.184 million yuan (non-Muslims 16.491 million yuan and Muslims 14.693 million yuan).

$$
\left\{\begin{array}{l}
\left.U_{0}\right|_{\theta_{0}=1, \theta_{1}=0} ^{\text {CFSX Equilibrium } 2} \geqslant\left. U_{0}\right|_{\theta_{0}=1, \theta_{1}=1} ^{\text {Perfect Equilibrium }} \\
\left.U_{1}\right|_{\theta_{0}=1, \theta_{1}=0} ^{\text {CFSX Equilibrium 2 }} \geqslant\left. U_{1}\right|_{\theta_{0}=1, \theta_{1}=1} ^{\text {Perfect Equilibrium }}
\end{array} .\right.
$$

1) Income and Welfare

To ensure that the welfare of Muslims and non-Muslims in CFSX equilibrium 2 is consistent with that under the perfect equilibrium, the HEV coefficients of Muslims and non-Muslims under CFSX equilibrium 2 and the perfect equilibrium are $0.000000 \%, 0.000000 \%$. The coefficients under CFSX equilibrium 2 and the benchmark equilibrium are $0.003306 \%$ and $0.003087 \%$. Under CFSX equilibrium 2, the welfare of both Muslims and non-Muslims is greater than that under the benchmark equilibrium.

Considering discounted income, the income of the non-Muslims and Muslims under CFSX equilibrium 2 in 2010 (466.534 and 492.688 billion yuan) is both less than that under the perfect equilibrium (469.683 and 496.028 billion yuan) and slightly larger than the values under the benchmark equilibrium (466.526 and 492.680 billion yuan). In terms of per capita annual income, the value of non-Muslims under CFSX equilibrium 2 is 5247.4 yuan and the value of Muslims is 3811.9 yuan, both less than those under the perfect equilibrium (5282.9 yuan and 3837.7 yuan). The per capita income of non-Muslims is higher than that of Muslims by $37.6584 \%$. Under CFSX equilibrium 2, savings reach 22,000 yuan.

2) Production

When the social welfare of Muslims and non-Muslims reaches the perfect equilibrium, the production values under CFSX equilibrium 2 differ from those under the perfect equilibrium. The three industrial outputs under CFSX equilibrium 2 are 107.865, 259.236 and 176.678 billion yuan, respectively, which are 108.002, 259.139, and 176.606 billion yuan under the perfect equilibrium. The output of the primary industry is lower than that under the perfect equilibrium, the outputs of the secondary and tertiary industries are higher than those under the perfect equilibrium, and output under CFSX equilibrium 2 (543.779 billion yuan) is higher than that under the perfect equilibrium (543.747 billion yuan). The wage rate of 2010 under CFSX equilibrium 2 is 1.170031 , lower than that under the perfect equilibrium (1.184373).

The labor inputs of the three industries under CFSX equilibrium 2 are 89.779, 46.858 and 89.616 billion yuan respectively. Compared with the labor input under the perfect equilibrium 
(89.891, 46.811, and 89.551 billion yuan), the labor force flows from the primary industry to the secondary and tertiary industries. Total capital investment under CFSX equilibrium 2 in the three industries is $2.821,204.411$, and 71.824 billion yuan respectively. Compared with the values under the perfect equilibrium $(2.827,204.369$, and 71.829 billion yuan), capital flows from the primary and tertiary industries to the secondary industry. Under the perfect equilibrium, return on capital increased from 1.000524 in 2009 to 1.011794 in 2010, whereas return on capital under CFSX equilibrium 2 reduces from 1.000000 to 0.999940.

3) Consumption

The consumption levels of Muslims and non-Muslims have generally changed and the demand of Muslims has increased to a greater extent. The demand of non-Muslims under CFSX equilibrium 2 in $2010(43.959,131.646$, and 88.339 billion yuan) is higher than that of the three industries under the perfect equilibrium $(43.489,130.290$, and 87.412 billion yuan). The demand of Muslims under CFSX equilibrium 2 in 2010 (63.906, 127.589, and 88.339 billion yuan) is lower than that under the perfect equilibrium (64.513, 128.849, and 89.194 billion yuan). The demand of Muslims and non-Muslims is further stimulated under CFSX equilibrium 2.

\subsection{Comparison of CFSX Equilibrium 1 and CFSX Equilibrium 2}

The goals of these two types of equilibria are inconsistent. The amount of assistance to Muslims and non-Muslims and total counterpart support are also inconsistent. Hence, to improve the lives of Muslims and non-Muslims, comparing and analyzing these two types of equilibria can help us choose a more reasonable way of providing counterpart support.

1) Income and Welfare

The difference between the social welfare of Muslims and non-Muslims under CFSX equilibrium 1 (84.963981 and 86.304367 billion) and CFSX equilibrium 2 (84.965077 and 86.304367 billion) is mainly reflected in the welfare of non-Muslims. The income of Muslims and nonMuslims under CFSX equilibrium 1 (466.529 and 492.689 billion yuan) and CFSX equilibrium 2 (466.533 and 492.688 billion yuan) is also different. Income under CFSX equilibrium 2 (959.221 billion yuan) is higher than that under CFSX equilibrium 1 (959.218 billion yuan). For Muslims, there is nearly no difference in the two cases. However, for non-Muslims, the CFSX equilibrium 2 case is better than the CFSX equilibrium 1 case.

In terms of per capita income, the values for Muslims and non-Muslims under the perfect equilibrium are 5282.9 yuan and 3837.7 yuan; under the two CFSX equilibria, the values are 5247.4 yuan and 3811.9 yuan; hence, the income of non-Muslims is higher than that of Muslims by $37.6584 \%$ in all three cases. Note that the per capita annual income of Muslims and nonMuslims is the same under the two CFSX equilibria.

2) Production

The amount of assistance for CFSX equilibrium 2 is higher, and more investment is reflected in production. The outputs of the three industries in 2010 under CFSX equilibrium 2 (107.865, 259.236, and 176.678 billion yuan) are slightly higher than those under CFSX equilibrium 1 (107.865, 259.231, and 176.676 billion yuan), whereas total output under CFSX equilibrium 2 (543.779 billion yuan) is higher than that under CFSX equilibrium 1 (543.772 billion yuan). The wage rates under the two types of equilibria are the same.

In 2010, there is no significant difference between the CFSX equilibria for the labor input: 
CFSX equilibrium 2 (89.779, 46.858 and 89.616 billion yuan) and CFSX equilibrium 1 (89.779, 46.858 and 89.616 billion yuan). So it is with capital investment: CFSX equilibrium 2 (2.821, 204.411, and 71.823 billion yuan) and CFSX equilibrium 1 (2.821, 204.406, and 71.824 billion yuan). At the same time, under these two equilibria, return on capital declines. In CFSX equilibrium 1, return on capital decreases from 1.000000 in 2009 to 0.999952 in 2010, and in CFSX equilibrium 2, return on capital falls from 1.000000 in 2009 to 0.999940 in 2010. Hence, the decline in returns is even more pronounced in CFSX equilibrium 2.

3) Consumption

Under the two types of equilibria, the consumption needs of Muslims and non-Muslims in the three industries make no difference. The consumption needs of the three industries for the non-Muslims in 2010 are nearly the same under CFSX equilibrium 1 (43.958, 131.643, and 88.337 billion yuan) and CFSX equilibrium $2(43.959,131.646$, and 88.339 billion yuan). This is similar to the case for Muslims: CFSX equilibrium 1 (63.906, 127.588, and 88.338 billion yuan) and CFSX equilibrium 2 (63.906, 127.589, and 88.339 billion yuan). The total consumption demand of non-Muslims and Muslims is both slightly higher under CFSX equilibrium 2.

In summary, compared with CFSX equilibrium 1, CFSX equilibrium 2 takes the social welfare of Muslims and non-Muslims into account and the performance of production and consumption is slightly better than that under CFSX equilibrium 1. Hence, this analysis shows that the paradox relating to RIFS has always existed in Xinjiang.

\section{Sensitivity Analysis}

This sensitivity analysis analyzes the impact of changes in the total growth rate of counterpart support on the social welfare and income of Muslims and non-Muslims in Xinjiang as well as the impact on production and consumption.

\subsection{CFSX Equilibrium 1}

On the basis of CFSX equilibrium 1, this paper simulates the investment growth of counterpart support in Xinjiang (Table 4). Each of the 10 simulations increases $100 \%$ compared with the previous simulation. Figure 1 shows social welfare for Muslims and non-Muslims.

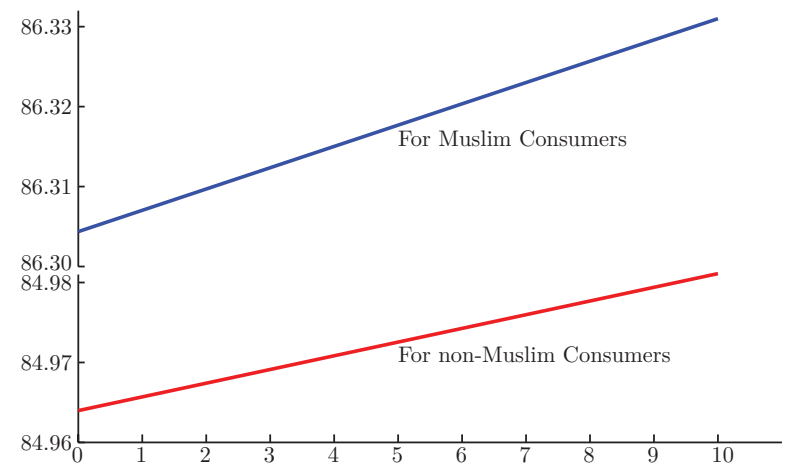

Figure 1 Social welfare for CFSX Equilibrium 1 
Table 4 CFSX Equilibrium 1

\begin{tabular}{|c|c|c|c|c|c|c|c|c|c|c|c|c|}
\hline & & $\begin{array}{c}\text { CFSX equi- } \\
\text { librium } 1\end{array}$ & $\begin{array}{c}\text { Case 1: } \\
100 \%\end{array}$ & $\begin{array}{c}\text { Case 2: } \\
200 \%\end{array}$ & $\begin{array}{c}\text { Case } 3: \\
300 \%\end{array}$ & $\begin{array}{c}\text { Case 4: } \\
400 \%\end{array}$ & $\begin{array}{c}\text { Case } 5: \\
500 \%\end{array}$ & $\begin{array}{c}\text { Case 6: } \\
600 \%\end{array}$ & $\begin{array}{c}\text { Case 7: } \\
700 \%\end{array}$ & $\begin{array}{c}\text { Case 8: } \\
800 \%\end{array}$ & $\begin{array}{c}\text { Case 9: } \\
900 \%\end{array}$ & $\begin{array}{c}\text { Case 10: } \\
1000 \%\end{array}$ \\
\hline \multirow{3}{*}{ Price } & The primary industry & 1.000002 & 1.000004 & 1.000006 & 1.000008 & 1.000010 & 1.000012 & 1.000014 & 1.000017 & 1.000019 & 1.000021 & 1.000023 \\
\hline & The secondary industry & 0.999963 & 0.999925 & 0.999888 & 0.999850 & 0.999813 & 0.999776 & 0.999738 & 0.999701 & 0.999663 & 0.999626 & 0.999589 \\
\hline & The tertiary industry & 0.999982 & 0.999965 & 0.999947 & 0.999929 & 0.999912 & 0.999894 & 0.999877 & 0.999859 & 0.999841 & 0.999824 & 0.999806 \\
\hline \multirow{3}{*}{ Production } & The primary industry & 107.865 & 107.866 & 107.868 & 107.870 & 107.871 & 107.873 & 107.875 & 107.876 & 107.878 & 107.880 & 107.881 \\
\hline & The secondary industry & 259.231 & 259.248 & 259.264 & 259.281 & 259.297 & 259.314 & 259.330 & 259.347 & 259.363 & 259.380 & 259.396 \\
\hline & The tertiary industry & 176.676 & 176.683 & 176.690 & 176.697 & 176.703 & 176.710 & 176.717 & 176.724 & 176.731 & 176.738 & 176.745 \\
\hline & Wage Rate & 1.170030 & 1.170034 & 1.170038 & 1.170042 & 1.170046 & 1.170050 & 1.170054 & 1.170058 & 1.170062 & 1.170066 & 1.170070 \\
\hline \multirow{3}{*}{ Labor Inputs } & The primary industry & 89.779 & 89.780 & 89.781 & 89.782 & 89.783 & 89.784 & 89.785 & 89.787 & 89.788 & 89.789 & 89.790 \\
\hline & The secondary industry & 46.858 & 46.857 & 46.856 & 46.856 & 46.855 & 46.854 & 46.853 & 46.852 & 46.851 & 46.850 & 46.850 \\
\hline & The tertiary industry & 89.616 & 89.616 & 89.616 & 89.615 & 89.615 & 89.615 & 89.614 & 89.614 & 89.614 & 89.614 & 89.613 \\
\hline \multicolumn{2}{|c|}{ Capital Return } & 0.999952 & 0.999903 & 0.999855 & 0.999807 & 0.999758 & 0.999710 & 0.999661 & 0.999613 & 0.999565 & 0.999516 & 0.999468 \\
\hline \multirow{3}{*}{ Capital Inputs } & The primary industry & 2.821 & 2.822 & 2.822 & 2.822 & 2.823 & 2.823 & 2.823 & 2.824 & 2.824 & 2.824 & 2.825 \\
\hline & The secondary industry & 204.406 & 204.424 & 204.441 & 204.459 & 204.476 & 204.494 & 204.511 & 204.529 & 204.546 & 204.564 & 204.581 \\
\hline & The tertiary industry & 71.823 & 71.830 & 71.837 & 71.844 & 71.852 & 71.8589 & 71.866 & 71.873 & 71.880 & 71.888 & 71.895 \\
\hline \multirow{3}{*}{$\begin{array}{l}\text { Non-Muslims' } \\
\text { consumption } \\
\text { demand }\end{array}$} & The primary industry & 43.958 & 43.959 & 43.959 & 43.959 & 43.9560 & 43.960 & 43.961 & 43.961 & 43.961 & 43.962 & 43.962 \\
\hline & The secondary industry & 131.643 & 131.651 & 131.659 & 131.666 & 131.674 & 131.682 & 131.689 & 131.697 & 131.705 & 131.712 & 131.720 \\
\hline & The tertiary industry & 88.337 & 88.340 & 88.343 & 88.346 & 88.349 & 88.352 & 88.355 & 88.358 & 88.361 & 88.364 & 88.367 \\
\hline \multirow{3}{*}{$\begin{array}{l}\text { Muslims' } \\
\text { consumption } \\
\text { demand }\end{array}$} & The primary industry & 63.906 & 63.908 & 63.909 & 63.910 & 63.911 & 63.913 & 63.914 & 63.915 & 63.917 & 63.918 & 63.919 \\
\hline & The secondary industry & 127.588 & 127.597 & 127.606 & 127.615 & 127.624 & 127.632 & 127.641 & 127.650 & 127.659 & 127.668 & 127.677 \\
\hline & The tertiary industry & 88.338 & 88.342 & 88.346 & 88.350 & 88.354 & 88.358 & 88.362 & 88.366 & 88.370 & 88.374 & 88.378 \\
\hline \multirow{2}{*}{$\begin{array}{l}\text { Income } \\
\text { (billion) }\end{array}$} & Non-Muslims (2010) & 263.933 & 263.937 & 263.942 & 263.947 & 263.951 & 263.956 & 263.960 & 263.965 & 263.967 & 263.974 & 263.979 \\
\hline & Muslims (2010) & 279.827 & 279.835 & 279.842 & 279.850 & 279.858 & 279.866 & 279.874 & 279.882 & 279.890 & 279.897 & 279.905 \\
\hline \multirow{4}{*}{$\begin{array}{l}\text { Social } \\
\text { welfare } \\
\text { (billion) }\end{array}$} & Welfare (non-Muslims) & 84.964 & 84.966 & 84.967 & 84.969 & 84.971 & 84.973 & 84.974 & 84.976 & 84.978 & 84.979 & 84.981 \\
\hline & Welfare (Muslims) & 86.304 & 86.307 & 86.310 & 86.312 & 86.315 & 86.318 & 86.320 & 86.323 & 86.326 & 86.328 & 86.331 \\
\hline & Non-Muslims (2010) & 94.453 & 94.457 & 94.461 & 94.465 & 94.469 & 94.473 & 94.477 & 94.481 & 94.485 & 94.489 & 94.493 \\
\hline & Muslims (2010) & 96.267 & 96.272 & 96.277 & 96.281 & 96.287 & 96.291 & 96.296 & 96.301 & 96.306 & 96.311 & 96.316 \\
\hline \multirow{2}{*}{$\mathrm{HEV}$} & Non-Muslims & & 0.000020 & 0.000040 & 0.000060 & 0.000081 & 0.000101 & 0.000121 & 0.000141 & 0.000161 & 0.000181 & 0.000202 \\
\hline & Muslims & & 0.000031 & 0.000062 & 0.000093 & 0.000123 & 0.000154 & 0.000185 & 0.000216 & 0.000247 & 0.000278 & 0.000309 \\
\hline \multirow{3}{*}{$\begin{array}{l}\text { CFSX } \\
\text { (billion) }\end{array}$} & Value & 0.025027 & 0.050054 & 0.075081 & 0.100108 & 0.125135 & 0.150162 & 0.175189 & 0.200216 & 0.225243 & 0.250270 & 0.275297 \\
\hline & Non-Muslims & 0.010199 & 0.020399 & 0.030598 & 0.040797 & 0.050997 & 0.061196 & 0.071396 & 0.081595 & 0.091794 & 0.101994 & 0.112193 \\
\hline & Muslims & 0.014828 & 0.029655 & 0.044483 & 0.059310 & 0.074138 & 0.088966 & 0.103793 & 0.118621 & 0.133449 & 0.148276 & 0.163104 \\
\hline \multirow{2}{*}{ Savings } & Non-Muslims & 0.001347 & 0.002695 & 0.004042 & 0.005389 & 0.006735 & 0.008082 & 0.009428 & 0.010775 & 0.012121 & 0.013467 & 0.014812 \\
\hline & Muslims & -0.001347 & -0.002695 & -0.004042 & -0.005389 & -0.006735 & -0.008082 & -0.009428 & -0.010775 & -0.012121 & -0.013467 & -0.014812 \\
\hline
\end{tabular}


1) Income and Welfare

The social welfare of Muslims and non-Muslims increases with a rise of in counterpart support. The social welfare of Muslims rises at a rate of 1.5304 times that of non-Muslims. The total welfare of non-Muslims under CFSX equilibrium 1, Scenario 5, and Scenario 10 are 84.964, 84.973 , and 84.981 billion, respectively. The total welfare of Muslims under CFSX equilibrium 1, Scenario 5, and Scenario 10 are 86.304, 86.318, and 86.331 billion. The HEV coefficient shows that the welfare of Muslims rises faster than that of non-Muslims. The discounted income of non-Muslims gradually decreases with the expansion of counterpart support, whereas the income of Muslims rises. For the 10-period simulation, savings grow in a nearly linear fashion. With an increase in counterpart support, the per capita income of Muslims and non-Muslims remains almost unchanged. Overall, with an increase in counterpart support, the income of non-Muslims decreases, whereas the income of Muslims increases, but the difference in the per capita annual income of individuals is small.

In the case of CFSX equilibrium 1, the main target of the support is Muslims, whose social welfare and income of Muslims are constantly. The welfare of non-Muslims expands, whereas total income reduces.

2) Production

For the 10-period simulation, with an increase in counterpart support, the output of the three industries in Xinjiang all increase, especially the secondary industry, followed by the tertiary industry. In period 10, output is $107.881,259.396$ and 176.744 billion yuan, and the three industrial outputs of CFSX equilibrium 1 are 107.865, 259.231 and 176.676 billion yuan. In the 10-stage simulation, wage rate increases slightly from 1.170030 to 1.170070 . With an increase in investment, the labor force increases slightly in the primary industry and decreases in the secondary and tertiary industries. As support expands the labor force flows from the secondary and tertiary industries to the primary industry, and return on capital falls gradually. The values from CFSX equilibrium 1 and case 10 are 0.999952 and 0.999468 respectively. With an increase in counterpart support, there is more capital investment in all three industries, especially the secondary industry.

3) Consumption

With an increase in investment, the consumption demand of non-Muslims increases slightly in all three industries, especially the secondary industry. In CFSX equilibrium 1, the consumption demand of non-Muslims in the three industries is $43.958,131.643$ and 88.337 billion yuan respectively. In case 10, the values are $43.963,131.720$ and 88.367 billion yuan. The consumer demand of Muslims also increases in the three industries, with demand in the secondary industry rising the fastest. In CFSX equilibrium 1, the consumption demand of Muslims in the three industries is $63.906,127.588$ and 88.338 billion yuan respectively. In case 10 , the values are $63.919,127.677$ and 88.378 billion yuan. With growth in counterpart support, the gap between demand for Muslims and non-Muslims in the primary and tertiary industries widens, whereas the gap for the secondary industries has decreases.

In summary, with an increase in support, the social welfare and income of the Muslims greatly improves, whereas the welfare of non-Muslims rises but their income decreases. Capital investment slightly increases and labor flows from the secondary and tertiary industries to the 
primary industry. Muslims thus choose more consumption. CFSX equilibrium 1 pays more attention to improving the benefits of Muslims, while the benefits for non-Muslims are easily overlooked.

\subsection{CFSX equilibrium 2}

On the basis of CFSX equilibrium 2, this paper again simulates the investment growth in counterpart support in Xinjiang. Table 5 reports the results and Figure 2 shows social welfare for Muslims and non-Muslims.

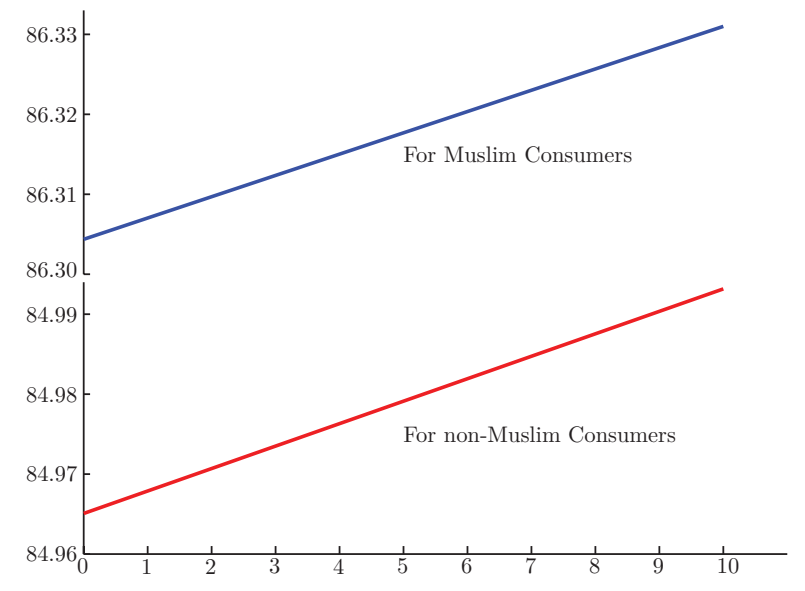

Figure 2 Social welfare for CFSX Equilibrium 1

1) Income and Welfare

The welfare of Muslims and non-Muslims under CFSX equilibrium 2 is consistent with the perfect equilibrium. Therefore, the simulation results for CFSX equilibria 1 and 2 are inconsistent. As shown in Figure 2, the welfare of both Muslims and non-Muslims is growing in a nearly linear manner and the rate of growth is similar. The welfare growth rate of non-Muslims is about 1.0700 times that of Muslims. The total welfare levels of non-Muslims under CFSX equilibrium 2, Scenario 5, and Scenario 10 are 84.965, 84.979, and 84.993 billion, respectively. The total welfare level of Muslims under CFSX equilibrium 2, Scenario 5, and Scenario 10 are 86.304, 86.318, and 86.331 billion. Compared with CFSX equilibrium 1, with an increase in investment, total welfare in CFSX equilibrium 2 is greater and the growth rate is faster. The HEV coefficient shows that the welfare of non-Muslims rises faster than that of Muslims in contrast to CFSX equilibrium 1.

In the simulation of investment in CFSX equilibrium 2, the income of non-Muslims and Muslims increases linearly. The growth rate of income of Muslims is lower than that under CFSX equilibrium 1, whereas the per capita income of Muslims and non-Muslims remains almost unchanged.

Overall, with rising counterpart support, Muslims and non-Muslims receive higher social welfare and income, and their per capita annual income is unchanged; in oher words, the expansion of investment growth does not change the income gap. 
Table 5 CFSX Equilibrium 2

\begin{tabular}{|c|c|c|c|c|c|c|c|c|c|c|c|c|}
\hline & & $\begin{array}{c}\text { CFSX equi- } \\
\text { librium } 2\end{array}$ & $\begin{array}{c}\text { Case 1: } \\
100 \%\end{array}$ & $\begin{array}{c}\text { Case 2: } \\
200 \%\end{array}$ & $\begin{array}{c}\text { Case } 3: \\
300 \%\end{array}$ & $\begin{array}{c}\text { Case 4: } \\
400 \%\end{array}$ & $\begin{array}{c}\text { Case } 5: \\
500 \%\end{array}$ & $\begin{array}{c}\text { Case 6: } \\
600 \%\end{array}$ & $\begin{array}{l}\text { Case 7: } \\
700 \%\end{array}$ & $\begin{array}{l}\text { Case 8: } \\
800 \%\end{array}$ & $\begin{array}{c}\text { Case 9: } \\
900 \%\end{array}$ & $\begin{array}{c}\text { Case 10: } \\
1000 \%\end{array}$ \\
\hline \multirow{3}{*}{ Price } & The primary industry & 1.000003 & 1.000005 & 1.000008 & 1.000010 & 1.000013 & 1.000016 & 1.000018 & 1.000021 & 1.000023 & 1.000026 & 1.000029 \\
\hline & The secondary industry & 0.999954 & 0.999907 & 0.999861 & 0.999815 & 0.999768 & 0.999722 & 0.999676 & 0.999629 & 0.999583 & 0.999537 & 0.999490 \\
\hline & The tertiary industry & 0.999978 & 0.999956 & 0.999935 & 0.999913 & 0.999891 & 0.999869 & 0.999847 & 0.999825 & 0.999804 & 0.999782 & 0.999760 \\
\hline \multirow{4}{*}{ Production } & The primary industry & 107.865 & 107.867 & 107.869 & 107.871 & 107.873 & 107.875 & 107.877 & 107.879 & 107.881 & 107.883 & 107.884 \\
\hline & The secondary industry & 259.236 & 259.256 & 259.277 & 259.297 & 259.318 & 259.339 & 259.359 & 259.380 & 259.400 & 259.421 & 259.442 \\
\hline & The tertiary industry & 176.678 & 176.686 & 176.695 & 176.703 & 176.7121 & 176.721 & 176.729 & 176.738 & 176.747 & 176.755 & 176.764 \\
\hline & Wage Rate & 1.170031 & 1.170036 & 1.170041 & 1.170046 & 1.170051 & 1.170056 & 1.170061 & 1.170066 & 1.170071 & 1.170076 & 1.170081 \\
\hline \multirow{3}{*}{ Labor Inputs } & The primary industry & 89.7789 & 89.780 & 89.781 & 89.783 & 89.784 & 89.785 & 89.787 & 89.788 & 89.789 & 89.791 & 89.792 \\
\hline & The secondary industry & 46.858 & 46.857 & 46.856 & 46.855 & 46.854 & 46.853 & 46.852 & 46.851 & 46.850 & 46.849 & 46.848 \\
\hline & The tertiary industry & 89.616 & 89.616 & 89.616 & 89.615 & 89.615 & 89.615 & 89.614 & 89.614 & 89.614 & 89.613 & 89.613 \\
\hline \multicolumn{2}{|r|}{ Capital Return } & 0.999940 & 0.999880 & 0.999820 & 0.999760 & 0.999700 & 0.999641 & 0.999581 & 0.999521 & 0.999461 & 0.999401 & 0.999341 \\
\hline \multirow{3}{*}{ Capital Inputs } & The primary industry & 2.821 & 2.822 & 2.822 & 2.823 & 2.823 & 2.823 & 2.824 & 2.824 & 2.825 & 2.825 & 2.825 \\
\hline & s The secondary industry & 204.411 & 204.432 & 204.454 & 204.476 & 204.498 & 204.520 & 204.541 & 204.563 & 204.585 & 204.607 & 204.629 \\
\hline & The tertiary industry & 71.824 & 71.833 & 71.842 & 71.851 & 71.860 & 71.869 & 71.878 & 71.887 & 71.896 & 71.905 & 71.914 \\
\hline \multirow{3}{*}{$\begin{array}{l}\text { Non-Muslims' } \\
\text { consumption } \\
\text { demand }\end{array}$} & The primary industry & 43.959 & 43.960 & 43.960 & 43.961 & 43.962 & 43.963 & 43.964 & 43.965 & 43.966 & 43.967 & 43.967 \\
\hline & The secondary industry & 131.646 & 131.657 & 131.667 & 131.678 & 131.689 & 131.699 & 131.710 & 131.720 & 131.731 & 131.741 & 131.752 \\
\hline & The tertiary industry & 88.339 & 88.343 & 88.348 & 88.352 & 88.356 & 88.361 & 88.365 & 88.370 & 88.374 & 88.378 & 88.383 \\
\hline \multirow{3}{*}{$\begin{array}{l}\text { Muslims' } \\
\text { consumption } \\
\text { demand }\end{array}$} & The primary industry & 63.906 & 63.907 & 63.908 & 63.910 & 63.911 & 63.912 & 63.913 & 63.914 & 63.915 & 63.916 & 63.917 \\
\hline & The secondary industry & 127.589 & 127.599 & 127.609 & 127.619 & 127.629 & 127.640 & 127.650 & 127.660 & 127.670 & 127.680 & 127.690 \\
\hline & The tertiary industry & 88.339 & 88.343 & 88.347 & 88.351 & 88.356 & 88.360 & 88.364 & 88.368 & 88.373 & 88.377 & 88.381 \\
\hline \multirow{2}{*}{$\begin{array}{l}\text { Income } \\
\text { (billion) }\end{array}$} & Non-Muslims (2010) & 263.936 & 263.944 & 263.952 & 263.960 & 263.968 & 263.975 & 263.983 & 263.991 & 263.999 & 264.007 & 264.015 \\
\hline & Muslims (2010) & 279.827 & 279.834 & 279.842 & 279.850 & 279.857 & 279.865 & 279.873 & 279.881 & 279.888 & 279.896 & 279.904 \\
\hline \multirow{4}{*}{$\begin{array}{l}\text { Social } \\
\text { welfare } \\
\text { (billion) }\end{array}$} & Welfare (non-Muslims) & 84.965 & 84.968 & 84.971 & 84.974 & 84.976 & 84.979 & 84.982 & 84.985 & 84.988 & 84.990 & 84.993 \\
\hline & Welfare (Muslims) & 86.304 & 86.307 & 86.310 & 86.312 & 86.315 & 86.318 & 86.320 & 86.323 & 86.3256 & 86.328 & 86.331 \\
\hline & Non-Muslims (2010) & 94.455 & 94.461 & 94.466 & 94.472 & 94.478 & 94.483 & 94.489 & 94.495 & 94.500 & 94.506 & 94.512 \\
\hline & Muslims (2010) & 96.268 & 96.273 & 96.278 & 96.284 & 96.289 & 96.294 & 96.299 & 96.305 & 96.310 & 96.315 & 96.321 \\
\hline \multirow{2}{*}{$\mathrm{HEV}$} & Non-Muslims & & 0.000033 & 0.000066 & 0.000099 & 0.000132 & 0.000165 & 0.000198 & 0.000231 & 0.000264 & 0.000298 & 0.000331 \\
\hline & Muslims & & 0.000031 & 0.000062 & 0.000093 & 0.000123 & 0.000154 & 0.000185 & 0.000216 & 0.000247 & 0.000278 & 0.000309 \\
\hline \multirow{3}{*}{$\begin{array}{l}\text { CFSX } \\
\text { (billion) }\end{array}$} & Value & 0.031184 & 0.062367 & 0.093551 & 0.124734 & 0.155918 & 0.187102 & 0.218285 & 0.249469 & 0.280652 & 0.311836 & 0.343020 \\
\hline & Non-Muslims & 0.016491 & 0.032981 & 0.049472 & 0.065963 & 0.082453 & 0.098944 & 0.115434 & 0.131925 & 0.148416 & 0.164906 & 0.181397 \\
\hline & Muslims & 0.014693 & 0.029386 & 0.044079 & 0.058772 & 0.073465 & 0.088158 & 0.102851 & 0.117544 & 0.132237 & 0.146930 & 0.161623 \\
\hline \multirow{2}{*}{ Savings } & Non-Muslims & 0.000022 & 0.000044 & 0.000066 & 0.000088 & 0.000110 & 0.000132 & 0.000154 & 0.000175 & 0.000197 & 0.000219 & 0.000241 \\
\hline & Muslims & -0.000022 & -0.000044 & -0.000066 & -0.000088 & -0.000110 & -0.000132 & -0.000154 & -0.000175 & -0.00019 & -0.000219 & -0.000241 \\
\hline
\end{tabular}


2) Production

For all 10 Cases, the production output of the three industries increases, and the growth rate of the output of the secondary industry is about 4.3880 times that of the output of the primary industry. The growth rate of the output of the tertiary industry is about 2.6943 times that of the output of the primary industry. In case 10, the total output of the three industries (544.090 billion yuan) is greater than that in case 10 in CFSX equilibrium 1 (544.022 billion yuan). For all the cases, wage rate increases from 1.170031 to 1.170081 .

With the increase in investment, the labor force slightly increases in the primary industry and decreases in the secondary and tertiary industries. Further, as support expands, labor flows from the secondary and tertiary industries to the primary industry. The total labor input of the three industries in situation 10 under CFSX equilibrium 2 (226.253 billion yuan) is equal to the total output of the three industrial labor inputs in situation 10 under CFSX equilibrium 1 (226.253 billion yuan). Taking CFSX equilibrium 2, situation 5, and case 10 as examples, return on capital decreases from 0.999940 to 0.999641 in case 5 and then falls back to 0.999341 in case 10. Return on capital decreases with an increase in investment. As support to Xinjiang rises, there is more capital investment in all three industries, with investment in the secondary industry growing rapidly. In Table 5 , total capital investment in the three industries in situation 10 (279.368 billion yuan) is greater than that in Table 4 (279.301 billion yuan).

3) Consumption

In the simulation of investment growth in CFSX equilibrium 2, the consumption demand of Muslims and non-Muslims in the three industries is rising and growth is almost linear. It grows fastest in the secondary industry, followed by the tertiary industry and the primary industry. In CFSX equilibrium 2, the consumption demand of non-Muslims in all three industries is $43.959,131.646$ and 88.339 billion yuan respectively. In case 10 , the values are $43.967,131.752$ and 88.383 billion yuan. In CFSX equilibrium 2, the consumption demand of Muslims in the three industries is $63.906,127.589$ and 88.339 billion yuan respectively. In case 10, the values are $63.917,127.690$ and 88.381 billion yuan. The growth rate of the consumer demand of Muslims is slightly higher than that of non-Muslims. The consumption demand of Muslims and non-Muslims under CFSX equilibrium 2 is greater than that under CFSX equilibrium 1.

In summary, both Muslims and non-Muslims receive more income and social welfare under CFSX equilibrium 2; the production output, labor input and capital investment under CFSX equilibrium 2 are higher than those under CFSX equilibrium 1 and the consumption demand of Muslims and non-Muslims under CFSX equilibrium 2 is larger. The assistance method based on CFSX equilibrium 2 is thus better.

\section{Conclusion}

This paper establishes a CGE model to simulate the impact of the restrictions of the Islamic financial system and the subsequent applications of the CFSX on the income and social welfare of Xinjiang residents. We find that under the benchmark equilibrium, the annual per capita income of Muslims has long fallen behind that of non-Muslims in Xinjiang. However, in the perfect equilibrium model, the social welfare and income of Muslims and non-Muslims, especially Muslims, increase significantly compared with the benchmark case. Further, per 
capita annual income increases, production output rises, and the labor and capital factors are further allocated. The labor force is transferred to the primary industry, capital flows into the secondary industry, and consumption demand increases. Because of RIFS, the living standards and social welfare of Muslims are therefore limited.

Under CFSX equilibrium 1, which makes the welfare of Muslims consistent with that under the perfect equilibrium, counterpart support raises their income and consumption demand. However, the overall welfare gap between Muslims and non-Muslims widens, and the income of non-Muslims declines. CFSX Equilibrium 2, which aims to ensure that the welfare of both Muslims and non-Muslims is consistent with that under the perfect equilibrium, is conducive to improving social welfare and income. Moreover, production output, the labor and capital factors and consumption demand are all higher than that in CFSX Equilibrium 1, whereas there is no difference in per capita annual income between CFSX equilibria 1 and 2. With investment growth at CFSX equilibrium 1, we find that Muslims' social welfare and income rises, whereas the income of the non-Muslims is damaged to a certain extent. Social welfare growth is slow, industrial output increases, and the consumption demand of Muslims increases rapidly. With investment growth at CFSX equilibrium 2, both Muslims and non-Muslims obtain higher social welfare and income, the welfare growth rate is faster, and social welfare grows faster. Compared with CFSX equilibrium 1, total output also increases, capital obviously transfers to the secondary industry, the consumption demand of both Muslims and non-Muslims rises, and total consumption demand increases. In summary, CFSX equilibrium 2 is a better way to support Xinjiang.

In summary, the restrictions of the Islamic financial system create a paradox that harms the utility of Muslims. To mitigate this, the CFSX is a suitable policy for promoting the healthy development of Xinjiang's economy and maintaining harmony and stability in society.

\section{References}

[1] Dyck A, Zingales L G. Private benefits of control: An international comparison. Journal of Finance, 2007, 59(2): 537-600.

[2] Johnes J, Izzeldin M, Pappas V. A Comparison of Performance of Islamic and Conventional Banks 20042009. Journal of Economic Behavior and Organization, 2013, 103(S): 93-107.

[3] Porta R L, Lopez-de-Silanes F, Shleifer A, et al. Law and finance. Journal of Political Economy, 1998, 106(6): 1113-1155.

[4] Stulz R M, Williamson R. Culture, openness, and finance. Journal of Financial Economics, 2003, 70(3): 313-349.

[5] Arrow K J, Debreu G. Existence of an equilibrium for a competitive economy. Econometrica, 1954, 22(3): 265-290.

[6] Debreu G. Theory of value: An axiomatic analysis of economic equilibrium. New Heven, Yale University Press, 1959.

[7] Duffie D, Shafer W. Equilibrium in incomplete markets: I - A basic model of generic existence. Journal of Mathematical Economics, 1985, 14(3): 285-300.

[8] Werner J. Equilibrium in economies with incomplete financial markets. Journal of Economic Theory, 1985, 36(1): 110-119.

[9] Shoven J B, Whalley J. Applied general-equilibrium models of taxation and international trade: An introduction and survey. Journal of Economic Literature, 1984, 22(3): 1007-1051.

[10] Shoven J B, Whalley J. Applying general equilibrium. London: Cambridge University Press, 1992. 
[11] Whalley J, Zhang S M. VAT base broadening when the location of some consumption is mobile. Economics Letters, 2005, 87(2): 199-205.

[12] Whalley J, Zhang S M. A numerical simulation analysis of (Hukou) labour mobility restrictions in China. Journal of Development Economics, 2007, 2(83): 391-410.

[13] Huang H, Whalley J, Zhang S M. Exploring policy options in joint intertemporal-spatial trade models using an incomplete markets approach. Economic Theory, 2009, 41(1): 131-145.

[14] Yu J, Zhang S M. Optimal trade policy in tariff games with inside money. Economic Modelling, 2011, 28(4): 1604-1614.

[15] Riezman R, Whalley J, Zhang S M. Distance measures between free trade and autarky for the world economy. Economic Modelling, 2011, 28(4): 2000-2012.

[16] Whalley J, Zhang S M. Tax induced multiple equilibria. Applied Economics Letters, 2011, 18(15): 14691477.

[17] Huang H, Whalley J, Zhang S M. Multiple Nash equilibria in tariff games. Applied Economics Letters, 2013, 20(4): 332-342.

[18] Ji J J, Ye Z Q, Zhang S M. Welfare analysis on optimal enterprise tax rate in China. Economic Modelling, 2013, 33(1): 149-158.

[19] Riezman R, Whalley J, Zhang S M. Metrics capturing the degree to which individual economies are globalized. Applied Economics, 2013, 45(36): 5046-5061.

[20] Whalley J, Zhang S M. Parametric persistence of multiple equilibria in an economy directly calibrated to 5 equilibria. Economic Modelling, 2014, 41(1): 356-364.

[21] Wang H, Wang Y Y, Zhang S M. Numerical simulation on property tax reform: Evidence from China. Applied Economics, 2019, 51(20): 2172-2194. 